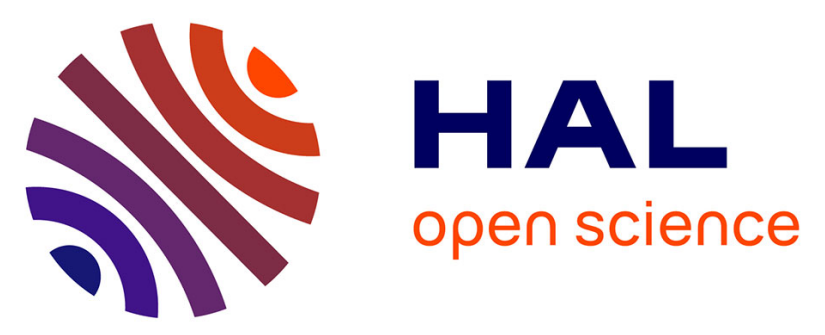

\title{
From molecular precursors in solution to microstructured optical fiber: a sol-gel polymeric route
} Hicham El Hamzaoui, Laurent Bigot, Géraud Bouwmans, Igor M. Razdobreev, Mohamed Bouazaoui, Bruno Capoen

\section{- To cite this version:}

Hicham El Hamzaoui, Laurent Bigot, Géraud Bouwmans, Igor M. Razdobreev, Mohamed Bouazaoui, et al.. From molecular precursors in solution to microstructured optical fiber: a sol-gel polymeric route. Optical Materials Express, 2011, 1 (2), pp.234. hal-00903846

\section{HAL Id: hal-00903846 \\ https://hal.science/hal-00903846}

Submitted on 13 Nov 2013

HAL is a multi-disciplinary open access archive for the deposit and dissemination of scientific research documents, whether they are published or not. The documents may come from teaching and research institutions in France or abroad, or from public or private research centers.
L'archive ouverte pluridisciplinaire HAL, est destinée au dépôt et à la diffusion de documents scientifiques de niveau recherche, publiés ou non, émanant des établissements d'enseignement et de recherche français ou étrangers, des laboratoires publics ou privés. 


\title{
From molecular precursors in solution to microstructured optical fiber: a Sol-gel polymeric route
}

\author{
Hicham El Hamzaoui,* Laurent Bigot, Géraud Bouwmans, Igor Razdobreev, \\ Mohamed Bouazaoui, and Bruno Capoen \\ Laboratoire PhLAM (CNRS, UMR 8523), IRCICA (USR CNRS 3380), CERLA (FR CNRS 2416), Université Lille 1- \\ Sciences et Technologies, Villeneuve d'Ascq Cedex F-59655, France \\ *hicham.elhamzaoui@phlam.univ-lille1.fr
}

\begin{abstract}
Solid-core photonic crystal fibers with the core derived from nondoped or Erbium-doped sol-gel silica rods are fabricated. The results demonstrate that the direct polymeric sol-gel route constitutes a promising method to prepare large high quality glass pieces that can be integrated into microstructured optical fibers suitable for passive and active optical fiber applications.
\end{abstract}

(C)2011 Optical Society of America

OCIS codes: (160.6060) Solgel; (160.6030) Silica; (160.5690) Rare-earth-doped materials; (060.2280) Fiber design and fabrication; (060.5295) Photonic crystal fibers; (060.2320) Fiber optics amplifiers and oscillators.

\section{References and links}

1. P. Kaiser and H. W. Astle, "Low-loss single-material fibres made from pure fused silica," Bell Syst. Tech. J. 53(6), 1021-1039 (1974).

2. J. C. Knight, J. Broeng, T. A. Birks, and P. S. J. Russell, "Photonic band gap guidance in optical fibers," Science 282(5393), 1476-1478 (1998).

3. D. J. DiGiovanni and R. S. Windeler, U.S. patent 5,907,652 (13 March 1998).

4. J. C. Knight, "Photonic crystal fibres," Nature 424(6950), 847-851 (2003).

5. A. Bjarklev, J. Broeng, and A. S. Bjarklev, Photonic Crystal Fibres, Kluwer Academic Publishers (2003), The Netherlands.

6. O. Frazão, J. L. Santos, F. M. Araújo, and L. A. Ferreira, "Optical sensing with photonic crystal fibers," Laser \& Photon. Rev. 2(6), 449-459 (2008).

7. J. Lægsgaard and A. Bjarklev, "Microstructured optical fibers-fundamentals and applications," J. Am. Ceram. Soc. 89(1), 2-12 (2006).

8. C. J. Brinker and G. W. Scherer, Sol-Gel Science, Academic Press: New York (1990).

9. L. L. Hench and J. K. West, "The sol-gel process," Chem. Rev. 90(1), 33-72 (1990).

10. J. H. Oh, United States Patent 6,519,976 (2003).

11. L. Costa and D. Kerner, "High purity glass forms by a colloidal sol-gel process," J. Sol-Gel Sci. Technol. 26(13), 63-66 (2003).

12. S. Bhandarkar, "Sol-gel processing for optical communication technology," J. Am. Ceram. Soc. 87(7), 11801199 (2004).

13. R. T. Bise and D. J. Trevor, Proc. Optical Fiber Commun. Conf (OFC), Washington, DC, Mar. 2005, vol. 3, invited paper OWL6, Optical Society of America.

14. W. Stręk, P. J. Dereń, K. Maruszewski, E. Pawlik, W. Wojcik, G. E. Malashkevich, and V. I. Gaishun, "Spectroscopic properties of erbium doped silica glasses obtained by sol-gel method," J. Alloy. Comp. 275-277, 420-423 (1998).

15. C. G. Guizard, A. C. Julbe, and A. Ayral, "Design of nanosized structures in sol-gel derived porous solids. Applications in catalyst and inorganic membrane preparation," J. Mater. Chem. 9(1), 55-65 (1999).

16. N. N. Khimich, G. M. Berdichevskii, E. N. Poddenezhnyi, V. V. Golubkov, A. A. Boiko, V. M. Ken'ko, O. B. Evreinov, and L. A. Koptelova, "Sol-gel synthesis of an optical silica glass doped with rare-earth elements," Glass Phys. Chem. 33(2), 152-155 (2007).

17. H. El Hamzaoui, L. Courtheoux, V. Nguyen, E. Berrier, A. Favre, L. Bigot, M. Bouazaoui, and B. Capoen, "From porous silica xerogels to bulk optical glasses: The control of densification," Mater. Chem. Phys. 121(1-2), 83-88 (2010).

18. J. Schroeder, in: M. Tomozawa, R. Doremus (Eds), Treatise on Materials Sciences and Technology, Vol. 12, Academic Press, New York (1977), p. 157.

19. P. S. J. Russell, "Photonic-crystal fibers," J. Lightwave Technol. 24(12), 4729-4749 (2006).

20. K. Tajima, J. Zhou, K. Nakajima, and K. Sato, "Ultralow loss and long length photonic crystal fiber," J. Lightwave Technol. 22(1), 7-10 (2004). 
21. O. Humbach, H. Fabian, U. Grzesik, U. Haken, and W. Heitmann, "Analysis of OH absorption bands in synthetic silica," J. Non-Cryst. Solids 203, 19-26 (1996).

22. M.-C. Phan-Huy, J.-M. Moison, J. A. Levenson, S. Richard, G. Mélin, M. Douay, and Y. Quiquempois, "Surface roughness and light scattering in a small effective area microstructured fiber," J. Lightwave Technol. 27(11), 1597-1604 (2009).

23. S. Pal, A. Mandal, G. De, E. Trave, V. Bello, G. Mattei, P. Mazzoldi, and C. Sada, "Improved photoluminescence properties of sol-gel derived $\mathrm{Er}^{3+}$ doped silica films," J. Appl. Phys. 108(11), 113116 (2010).

24. E. Desurvire, "Erbium-Doped Fiber Amplifiers: Principles and Applications," John Wiley and Sons, Inc., New York (1994).

25. W. J. Miniscalco, "Erbium-doped glasses for fiber amplifiers at $1500 \mathrm{~nm}$," J. Lightwave Technol. 9(2), 234-250 (1991).

26. E. M. Pawlik, W. Stręk, P. J. Dereń, J. Wójcik, G. E. Malaskevich, and V. E. Gaishun, "Optical properties of erbium-doped silica fibers obtained by sol-gel method," Spectrochim. Acta A Mol. Biomol. Spectrosc. 55(2), 369-373 (1999).

27. B. Tortech, A. Gusarov, M. Van Uffelen, J. Bisutti, S. Girard, Y. Ouerdane, A. Boukenter, J. P. Meunier, F. Berghmans, and $\mathrm{H}$. Thienpont, "Pulsed X-ray and continuous gamma radiation effects on erbium doped optical fibers properties,” IEEE Trans. Nucl. Sci. 54(6), 2598-2603 (2007).

28. S. Girard, Y. Ouerdane, M. Bouazaoui, C. Marcandella, A. Boukenter, L. Bigot, and A. Kudlinski, in Symposium abstracts book: 8th symposium SiO2, Advanced Dielectrics and Related Devices, Varenna: Italy (2010).

29. J. Canning, E. Buckley, and K. Lyytikainen, "Propagation in air by field superposition of scattered light within a Fresnel fiber," Opt. Lett. 28(4), 230-232 (2003).

30. J. Canning, E. Buckley, and K. Lyytikainen, "Multiple source generation using air-structured optical waveguides for optical field shaping and transformation within and beyond the waveguide," Opt. Express 11(4), 347-358 (2003).

\section{Introduction}

Microstructured optical fibers, also known as photonic crystal fibers (PCFs) or holey fibers, have attracted growing interest during the last two decades owing to their wide range of optical properties accessible thanks to a freedom of designs that cannot be achieved with conventional fibers [1-5]. Due to these characteristics, they found a large variety of applications ranging from optical communication to light sources or sensing [6]. A welldocumented example of PCF geometry is high index core air/glass fiber, which contains, in its cladding, air holes extending along the entire fiber length and regularly arranged around a solid core. In this case, no refractive index profiling of the glass is required, light confinement being performed by the air holes. Even if this geometry made it possible to exploit all kinds of materials for the realization of PCFs, most of the realizations are based on air/silica arrangements, with a core composed of silica or doped silica glass. High purity silica used for these realizations is generally synthesized using techniques developed for conventional silica fibers, namely MCVD, VAD, or OVD [7]. Those methods lead to very good optical properties but, due to the nature of the halide precursors generally used, they impose to use high temperature conditions not compatible with the incorporation of a wide range of doping and without easy control of doping incorporation. For example, it is difficult, with these techniques, to achieve glass pieces with large cross sections (diameter larger than $2 \mathrm{~mm}$ ) homogeneously doped with elements like rare-earth ions that are needed for very high power fiber lasers. In order to propose an alternative approach, the use of the sol-gel process combined to PCF geometry could constitute an attractive method because both reactions and sintering of sol-gel silica can be carried out at low temperatures compared to those required for gaseous techniques. It also gives the possibility to control the composition, the homogeneity and reach a high concentration doping of the material [8,9]. In this context, solgel silica rods with a large cross section (diameter larger than $1 \mathrm{~cm}$ ) may be used as starting materials for the construction of PCFs.

There are two sol-gel approaches. The most often used for the fabrication of silica monoliths is called the colloidal route, which uses fumed silica particles in solution as starting material [10-12]. In this case, the gel formation is the result of hydrogen bonds between colloidal particles and the liquid, leading, after drying, to a porous structure characterized by random packing of spheres and shapeless aggregates. These characteristics make the continuous glass network formation only at sintering. The colloidal method has been employed recently in order to produce pure silica glasses [13]. It starts with fumed silica 
particles having specific surface area of $35-55 \mathrm{~m}^{2} \mathrm{~g}^{-1}$ as the primary silica source. The dried porous gel presents pores with an average pore size around $100 \mathrm{~nm}$ and a surface area of 45

$\mathrm{m}^{2} \mathrm{~g}^{-1}$. These materials were densified and used to fabricate microstructured fibers. It is worthy to note that the low specific area of these materials and the large diameter of the pores are not suitable for the incorporation of high concentration of dopants. Moreover, they suffer from the same limitations encountered with conventional silica (melting or MCVD methods) when doped with rare-earth ions in terms of quenching phenomena [14]. Beside this, polymeric route uses molecular precursors (alkoxides) as starting materials, the gelation process being a result of chemical reactions. Hence, the glass network being formed during this stage at room or slightly elevated temperature, it ensures a more homogeneous material and low sintering temperature [15]. Up to now, rapid densification rates and high shrinkage have impeded the preparation of large monolithic glass pieces without cracks. These difficulties have limited the use of the sol-gel polymeric route to the production of small glass samples of few millimeters dimensions or to the deposition of thin films [16]. However, recently we have demonstrated that the polymeric sol-gel route is a convenient method to prepare monolithic cracks-free silica nanoporous xerogels. These xerogels were successfully sintered in rod-shaped silica glasses of a few centimeters in diameter, with a high conversion rate of nearly $100 \%$ [17].

In this paper, we report on the use of the sol-gel polymeric route to prepare high purity silica glass rods for the realization of the core of a PCF. The optical properties of these sol-gel derived microstructured fibers are investigated in terms of losses and scattering. In addition, we report on preliminary results on the synthesis and characterization of Erbium-doped rods obtained via the sol-gel polymeric route and the use of these rods to fabricate a PCF with a pure silica Erbium-doped core. Effects of this synthesis on the spectroscopic properties of Erbium ions are discussed together with the results of the Erbium-doped PCF in amplification regime.

\section{Experimental}

Synthesis: For non-doped preforms, porous silica monoliths, shaped as rods, were prepared using a polymeric sol-gel technique from tetraethylorthosilicate (TEOS). The obtained xerogels were stabilized at $1000{ }^{\circ} \mathrm{C}$ before dehydration and densification to obtain glassy silica rods as already described elsewhere [17].

For Er-doped preforms, the stabilized silica xerogels, which exhibit interconnected pores, were soaked in alcoholic solutions of an erbium salt for $48 \mathrm{~h}$. Then, the samples were taken out and dried at $50{ }^{\circ} \mathrm{C}$ for several hours in order to remove solvents and to retain the erbium salt within the pores. The doped matrices were then dehydrated and densified under the same conditions as for non-doped preforms.

Scattering measurements: The scattered intensity was measured at $633 \mathrm{~nm}$ using a polarized He-Ne laser focused in order to achieve a uniform beam waist on the whole sample length. The sol-gel sample was immersed, together with a reference suprasil sample, into a glass tank filled with an index matching liquid. Both samples were mounted on the same translation stage, which allows the laser beam to probe them sequentially. The angular distribution of the scattered intensity for a given sample is also measured by a collecting arm, mounted on a goniometer, consisting in an afocal optical set-up that images the scattering volume on a photomultiplier tube after spatial filtering through a $500 \mu \mathrm{m}$ slit.

SEM characterizations: SEM images were taken using a Hitachi TM-1000 instrument.

Absorption measurements: For preforms, the absorption spectra were recorded at room temperature using a Perkin-Elmer lambda 19 UV-Vis-IR double beam spectrometer.

Attenuation measurements: The spectral attenuation of the fibers was measured by the conventional cut-back technique using a white light source and an optical spectrum analyzer. The fiber length used for this measurement was 120 and $2 \mathrm{~m}$ for non doped fiber and for Erdoped one respectively.

Photoluminescence measurements: The experiments on PL kinetics under pulsed excitation were performed in the photon-counting regime at room temperature with the use of 
a single-grating monochromator M266 (Solar LS) equipped with a nitrogen cooled photomultiplier R5509-73 (Hamamatsu Inc.) coupled to the multi-stop scaler P7887 (Fast ComTec). The excitation at $980 \mathrm{~nm}$ was performed with $5 \mathrm{~ns}$ pulses of $3 \mu \mathrm{J}$ energy and $10 \mathrm{~Hz}$ repetion rate from a tunable optical parametric oscillator (GWU) pumped by the second harmonique of a Nd:YAG laser (Quanta Ray, Spectra Physics Inc.).

For Er-doped PCFs, PL spectra have been recorded longitudinally on an optical spectrum analyzer in an all-fiber configuration by multiplexing a $977 \mathrm{~nm}$ pump source into the centimetric length fiber.

Amplification: Gain characteristics of the Er-doped PCF have been measured in an allfiber configuration by multiplexing into a $4.9 \mathrm{~m}$ long PCF a $977 \mathrm{~nm}$ pump source with a tunable laser diode (Agilent). Input/output spectra have been measured on an optical spectrum analyzer (Yokogawa) as a function of signal wavelength or pump power.

\section{Results and discussion}

\subsection{Pure Sol-gel silica core PCF}

Optical losses in glasses arise from both absorption and scattering phenomena. Usually, extrinsic absorption results from the presence of $\mathrm{OH}$ groups, transition metal ions or structural defect centers. Moreover, the presence of bubbles trapped inside the vitreous structure also constitutes a source of scattering. In order to obtain high-purity silica glass rods, xerogels prepared from TetraEthylOrthoSilicate (TEOS) at low hydrolysis ratio, were first stabilized at $1000^{\circ} \mathrm{C}$ in air to remove residual moisture and organics, and thereafter heat-treated under chlorine/oxygen atmosphere before densification. The consolidation process, leading to a dense transparent silica glass rod (Fig. 1), is performed under helium atmosphere and is described elsewhere [17]. The level of residual $\mathrm{OH}$ in the obtained silica glass was determined, using FTIR spectroscopy, to be below $500 \mathrm{ppb}$. Moreover, no residual chlorine has been evidenced by Energy Dispersive X-ray Spectroscopy (EDS) analysis: the Si-Cl bonds are efficiently broken during the oxidation step and the gaseous $\mathrm{Cl}_{2}$ is allowed to quit the matrix before the pore collapsing.

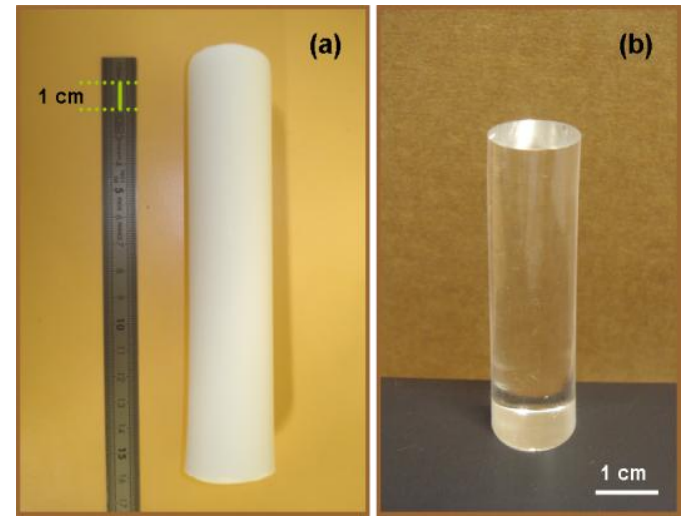

Fig. 1. (a) Photograph of the sol-gel silica xerogel stabilized at $1000{ }^{\circ} \mathrm{C}$ (b) silica glass rod prepared from this xerogel after dehydration and densification.

In the case of sol-gel samples prepared without special care to limit the presence of bubbles or other impurities, the high scattering losses would strongly limit all tentative use of these samples in a waveguide structure. In order to have insight to the potential use of a solgel polymeric route glass for optical fiber realization, the scattering signal of the obtained glass was measured and compared to the one of a Suprasil grade silica glass (from Heraeus) used as a reference. If a pure Rayleigh scattering regime is observed, Rayleigh scattering coefficient of the sample under investigation can be deduced from the comparison with that of the Suprasil sample of known Rayleigh coefficient. Pure Rayleigh scattering regime is characterized by a symmetrical angular distribution of scattered light. It has to be pointed out 
that Rayleigh scattering is the most important factor for the determination of background losses in transmission windows of silica optical glasses. This elastic scattering, which occurs even in the purest silica glass, regardless of its synthesis process, is attributed to large domains of density fluctuations [18]. Concerning the sol-gel sample, the scattering level is comparable to the one arising from the Suprasil glass (Fig. 2). Excluding the positions of the sol-gel rod interfaces and by averaging the signal intensity over the length of the sample, it is found that the scattering level of the rod-shaped silica glass produced using the polymeric sol-gel technique is about 3 times higher than the one of the Suprasil grade silica glass. The most probable origin of the excess scattering loss is the presence of residual nanopores in the solgel rod after densification. This could explain the slightly asymmetrical dependence of the scattered intensity as a function of angle, which underlines the non-pure Rayleigh scattering regime (Fig. 2).

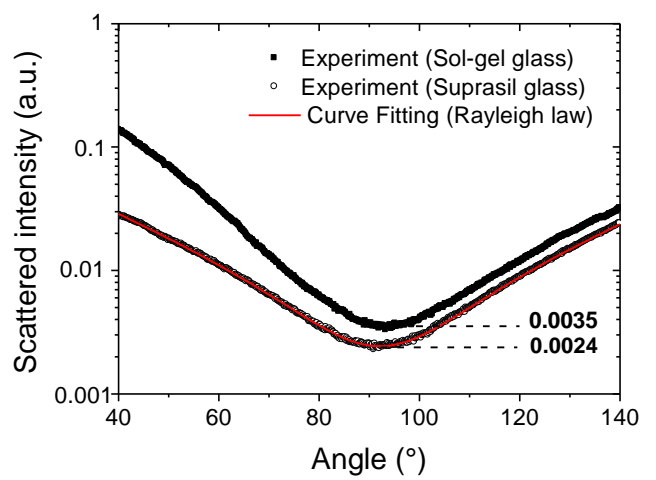

Fig. 2. Light scattered intensity of sol-gel and Suprasil glasses as a function of angle.

In order to use this sol-gel silica rod as a fiber core, an air/silica PCF has been realized using the conventional Stack and draw process [19]. During the fabrication, the sol-gel rod has been heated several times at high temperatures. At first, it was fused at both ends to Suprasil F300 tubes (Heraeus Tenevo LLC) in order to make it long enough for our drawing facilities. It was then drawn into $1.6 \mathrm{~mm}$ diameter rods at about $2000^{\circ} \mathrm{C}$. After that, the $25 \mathrm{~mm}$ diameter stack containing this rod in its center has been drawn into $4 \mathrm{~mm}$ canes at a furnace temperature of about $2060^{\circ} \mathrm{C}$. Finally, one of these canes has been sleeved into an $8 \mathrm{~mm}$ diameter tube and drawn into the final fiber at about $2000^{\circ} \mathrm{C}$. This fiber (SEM image presented in the inset of Fig. 3) has an outside diameter of $127 \mu \mathrm{m}$ for a core diameter of 6.4 $\mu \mathrm{m}$ defined as the distance between two diametrally opposed holes. The pitch of the periodic cladding, $\Lambda$, and the diameter of the air holes, $\mathrm{d}$, are $3.95 \mu \mathrm{m}$ and $1.7 \mu \mathrm{m}$, respectively. 


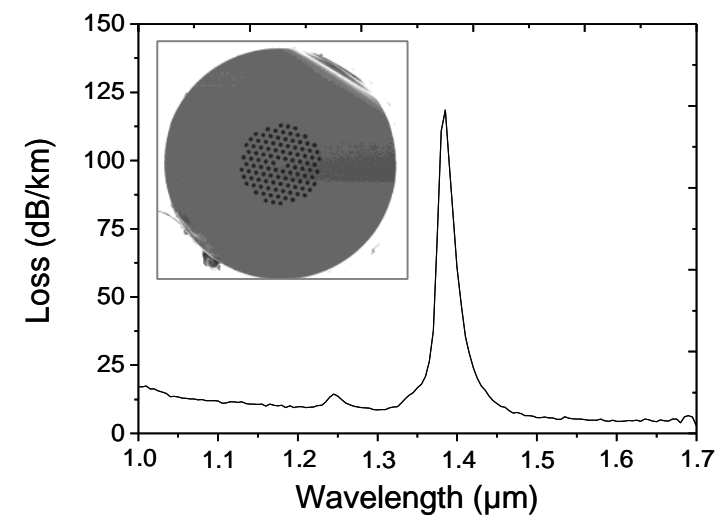

Fig. 3. Attenuation spectrum of undoped pure silica Sol-gel core PCF. In the inset, a Scanning Electron Microscope (SEM) image of the cross-section of pure silica sol-gel core PCF.

Figure 3 presents the attenuation spectrum of the fabricated sol-gel PCF. At $1.55 \mu \mathrm{m}$, optical attenuation of this fiber is about $8 \mathrm{~dB} / \mathrm{km}$. This value is clearly higher than record attenuation reported in a similar PCF realized from VAD materials [20] and slightly higher than the one obtained for a sol-gel PCF realized by the colloidal route [13]. However, it is comparable to the values obtained for PCF fabricated from commercial pure silica at the same conditions on our drawing facilities. This attenuation spectrum also shows the $\mathrm{OH}$-induced absorption peak of the order of $150 \mathrm{~dB} / \mathrm{km}$ at $1380 \mathrm{~nm}$. This attenuation value corresponds to an $\mathrm{OH}$ concentration of about $3 \mathrm{ppm}$ [21]. The $\mathrm{OH}$ impurities in a PCF are composed of the inherent $\mathrm{OH}$ impurities in the raw silica glass and those on the surface of the holes, which diffuse into the core region of the PCF at high temperature during the fabrication process. Hence, at the same conditions of fiber drawing, the undoped sol-gel PCF presents similar properties as the one performed using conventional high purity silica, even though the scattering loss level in the starting sol-gel rod was measured to be 3 times higher than in the Suprasil. This result could be explained by the fact that, before the achievement of the sol-gel PCF, the sol-gel rod was heat-treated several times at $2000^{\circ} \mathrm{C}$, which induces a collapsing of the remaining nanopores and hence the removal of the excess scattering loss discussed above. The PCF attenuation of about $8 \mathrm{~dB} \mathrm{~km}^{-1}$ at $1.55 \mu \mathrm{m}$ could be mainly caused by the surface roughness of the holes along the entire PCF length [22]. Further reduction of the roughness in the process is needed to reduce the optical attenuation. 


\subsection{Erbium-doped Sol-gel silica core PCF}

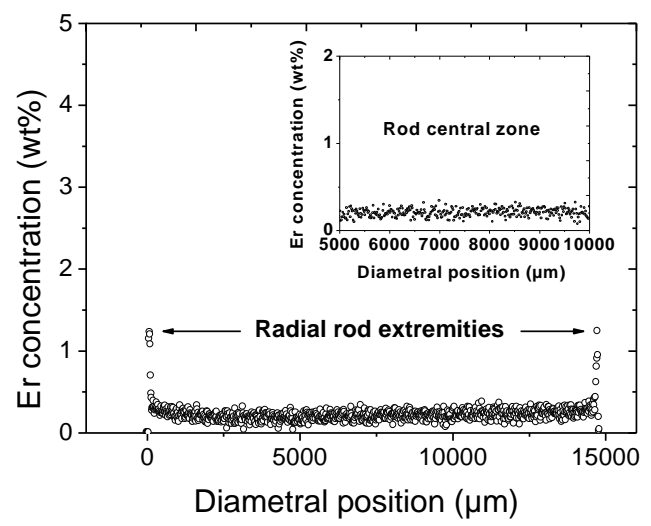

Fig. 4. Erbium concentration profile of $\mathrm{SiO}_{2} \mathrm{Er} 3$ preform determined using EPMA analysis. In the inset, a zoom in the rod central zone.

In order to prepare an Erbium-doped rod, a post-doping of the xerogel has been performed through a solution doping process. This was made possible thanks to the presence of interconnected nanopores inside our silica matrix, as shown by gas sorption analysis [17]. To this purpose, silica xerogel rods, stabilized at $1000^{\circ} \mathrm{C}$ with a pore size distribution centered on $24 \mathrm{~nm}$ and a total pore volume of $0.57 \mathrm{~cm}^{3} \mathrm{~g}^{-1}$, were soaked with alcoholic solutions of different erbium salt concentrations. To sinter these doped nanoporous matrices, we adopted the chemical dehydration and densification method used for pure silica glass fabrication. The obtained rods have been named $\mathrm{SiO}_{2} \mathrm{Er} 1, \mathrm{SiO}_{2} \mathrm{Er} 2$ and $\mathrm{SiO}_{2} \mathrm{Er} 3$, corresponding to the different solution concentrations and hence to the final erbium molar concentrations in silica $300 \mathrm{ppm}$, $600 \mathrm{ppm}$ and $900 \mathrm{ppm}(\mathrm{Er} / \mathrm{Si} \mathrm{mol})$, respectively. These mean concentrations were estimated using electron probe microanalysis (EPMA) (Fig. 4). One can note, except in the radial rod extremities, a quite homogeneous distribution of Erbium inside the cross section of the doped preform.

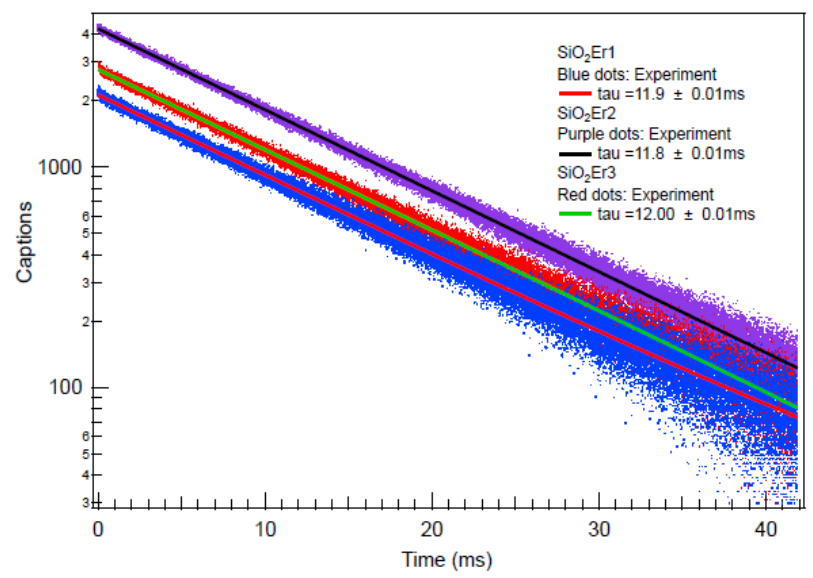

Fig. 5. Room temperature PL kinetics of ${ }^{4} \mathrm{I}_{13 / 2}$ state of $\mathrm{Er}^{3+}$ ions recorded at $1530 \mathrm{~nm}$ under excitation at $980 \mathrm{~nm}$ for $\mathrm{SiO}_{2} \mathrm{Er} 1, \mathrm{SiO}_{2} \mathrm{Er} 2$ and $\mathrm{SiO}_{2} \mathrm{Er} 3$ preforms.

Figure 5 reports the luminescence decay of the ${ }^{4} \mathrm{I}_{13 / 2}$ state of $\mathrm{Er}^{3+}$ ion in the $\mathrm{SiO}_{2} \mathrm{Er} 1$, $\mathrm{SiO}_{2} \mathrm{Er} 2$ and $\mathrm{SiO}_{2} \mathrm{Er} 3$ samples upon excitation at $980 \mathrm{~nm}$ and detection at $1530 \mathrm{~nm}$. One can note that for the three samples, no fast component is observed and the decay curves exhibit a 
single-exponential behavior with a lifetime of $12 \mathrm{~ms}$. This value is higher than the lifetime of $8 \mathrm{~ms}$ measured in $\mathrm{Er}^{3+}$ doped silica films [23], and remains even higher than those reported in aluminosilicate glasses, which are about $10 \mathrm{~ms}$ [24]. It is important to note that this lifetime is obtained for a relatively high Erbium concentration $(900 \mathrm{ppm})$ in pure silica, which indicates that no $\mathrm{Er}^{3+}$ ions cluster exists in the sol-gel derived vitreous matrix. Up to now, for such a concentration $(900 \mathrm{ppm})$, it was not possible to avoid the clustering of $\mathrm{Er}^{3+}$ ions inside the pure silica prepared by conventional melting and MCVD or colloidal sol-gel methods [14,25]. In the literature, there is only one report of conventional optical fibers doped with erbium prepared using colloidal sol-gel route, However, these fibers presented a high attenuation in the IR spectral range, preventing their use as amplifier media [26].

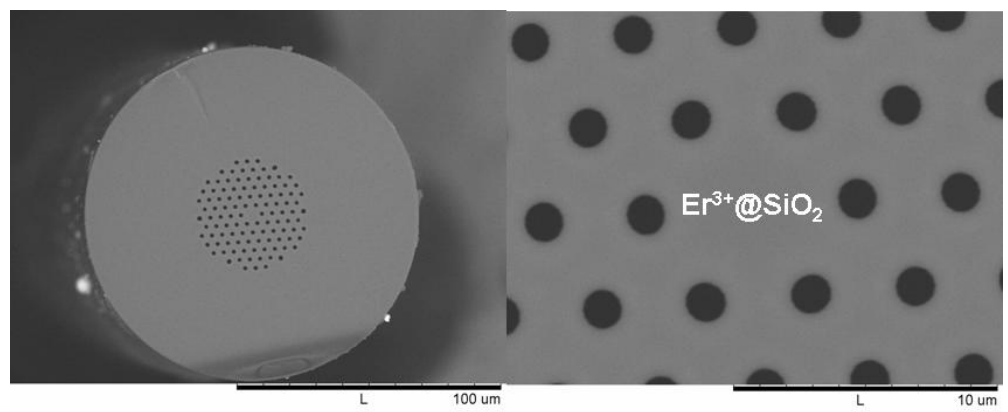

Fig. 6. Scanning Electron Microscope (SEM) image of the cross-section of PCFEr1 fiber (left). Zoom on this image showing the sol-gel Er-doped solid core of this fiber (right).

The PCFs drawn from rods $\mathrm{SiO}_{2} \mathrm{Er} 1$ and $\mathrm{SiO}_{2} \mathrm{Er} 3$, using the same process as for undoped PCF, were named PCFEr1 and PCFEr3 respectively. For these fibers, the cladding was a twodimensional photonic crystal made of silica with air holes running along the length of the fiber. The holes were arranged in a hexagonal honeycomb patterns across the cross section as shown in Fig. 6. For example, the pitch of the periodic cladding and the diameter of the air holes are $4 \mu \mathrm{m}$ and $1.5 \mu \mathrm{m}$, respectively for PCFEr1.
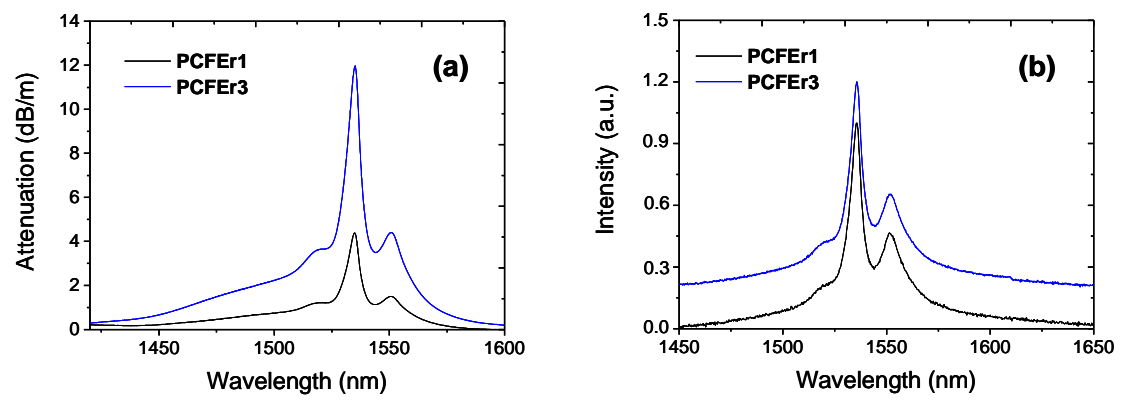

Fig. 7. Room temperature spectra of PCFEr1 and PCFEr3 microstructured fibers in the infrared region: (a) absorption spectra and (b) PL spectra upon excitation at $980 \mathrm{~nm}$.

Both attenuation and emission spectra of these fibers, shown in Fig. 7, exhibit a main peak at $1535 \mathrm{~nm}$, corresponding to the transition ${ }^{4} \mathrm{I}_{13 / 2} \leftrightarrow{ }^{4} \mathrm{I}_{15 / 2}$ of $\mathrm{Er}^{3+}$ ions. The shape of the emission band is the same for both samples, indicating that $\mathrm{Er}^{3+}$ ions occupy sites characterized by similar local surrounding, even though the Erbium ion concentration varies from $300 \mathrm{ppm}$ to $900 \mathrm{ppm}$. This is another indication that $\mathrm{Er}^{3+}$ ions are homogeneously distributed in the sol-gel derived silica matrix. Moreover, one can note that the Er-related absorption at $1535 \mathrm{~nm}\left(4.3 \mathrm{~dB} \mathrm{~m}^{-1}\right.$ and $12 \mathrm{~dB} \mathrm{~m}^{-1}$ for the fibers PCFEr1 and PCFEr3 respectively) is in good agreement with the Erbium content determined in the associated rods using EPMA analysis. 

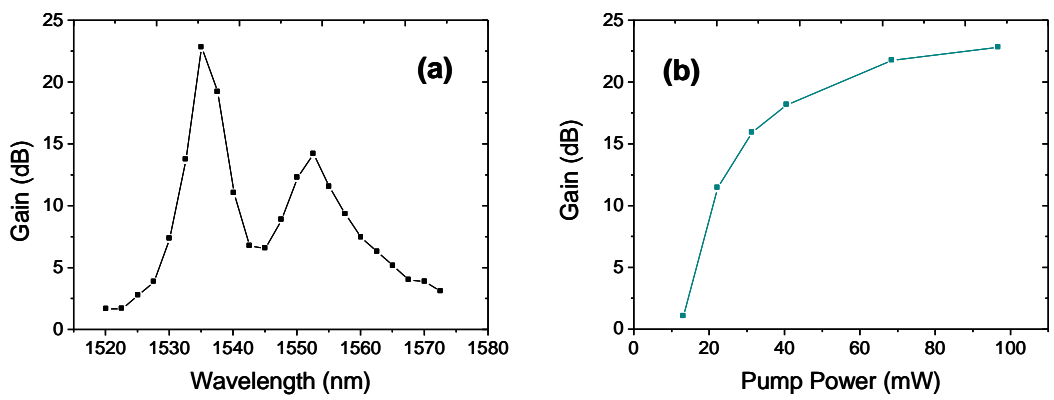

Fig. 8. (a) Gain profile at $122 \mathrm{~mW}$ and (b) gain at $1535 \mathrm{~nm}$, as function of pump power for the PCFEr3 fiber (4.9 $\mathrm{m}$ length fiber).

The amplification properties of the heavily doped fiber have been investigated in a $4.9 \mathrm{~m}$ length sample of PCFEr3 (900 ppm of Er). Figure 8a presents the gain profile of this fiber around $1.55 \mu \mathrm{m}$. A maximum gain of about $22.8 \mathrm{~dB}$ has been obtained at $1535 \mathrm{~nm}$. At this wavelength, the pump power dependence of the gain has also been investigated, as shown in Fig. 8 b. The saturated output gain in the range $23-25 \mathrm{~dB}$ was obtained from extrapolation of experimental data.

These interesting properties make the polymeric sol-gel-derived Er-doped silica PCF amplifier promising for applications under extreme conditions as photonic devices operating in space. Indeed, it has been shown recently that the presence of codoping atoms, such as Al or $\mathrm{P}$, in conventional Er-doped fiber amplifier makes them more sensitive to extreme conditions [27]. Hence, one could expect that, as it is the case for pure silica PCF [28], Erdoped pure silica PCF will be more resistant to extreme environment. Moreover, by using the polymeric sol-gel technique, glass pieces with large cross sections (diameter larger than $1 \mathrm{~cm}$ ) homogeneously doped with elements like rare-earth ions can be achieved for very high power fiber lasers. Such sol-gel glass pieces could be used also to fabricate non-periodic structured fibers $[29,30]$.

\section{Conclusion}

In conclusion, we have demonstrated that the polymeric sol-gel route can be used to fabricate a high-purity silica glass rod with good optical and mechanical properties. Thanks to these properties, the silica rod has been successfully integrated as a core in a PCF presenting good optical characteristics with optical losses around $8 \mathrm{~dB} \mathrm{~km}^{-1}$ at $1550 \mathrm{~nm}$. This procedure has been extended to prepare a highly Erbium-doped silica rod (up to 900 ppm without $\mathrm{Er}^{3+}$ ions clustering). These rods were used to fabricate Erbium-doped PCFs suitable as gain media, with a quite uniform distribution of erbium in the host matrix. Finally, using either a soldoping or a post-doping method by exploiting the presence of interconnected nanopores inside the stabilized silica xerogels, other active elements could be loaded before dehydration and consolidation to a doped silica glass, which can be incorporated inside active or passive PCF.

\section{Acknowledgments}

The authors acknowledge K. Delplace for the technical assistance. This work was supported by the Ministère Chargé de la Recherche, the Région Nord/Pas de Calais, and by the Fonds Européen de Développement Economique des Régions. 